\title{
PENGENDALIAN MONETER DENGAN SISTEM NILAI TUKAR FLEKSIBEL DAN INFLASI SEBAGAI SASARAN TUNGGAL
}

Overview

\author{
Wijoyo Santoso*)
}

Parapembaca Bulletin Ekonomi Moneter dan Perbankan (BEMP) yang budiman, dalam edisi keenam sejak lahirnya bulletin kuartalan ini, yakni pada bulan Juli 1998, kita kembali ingin membahas berbagai aspek pengendalian moneter dari berbagai aspek yang cukup relevan dengan sasaran akhir tunggal yakni inflasi. Pada edisi pertama bulletin ini (Volume 1 Nomor 1, Juli 1998) kita sudah membahas secara mendalam mengenai beberapa pemikiran baru dalam manajemen moneter di Indonesia khususnya menyangkut kerangka teori dan dasar-dasar filosofisnya. Edisi sekarang ini menyajikan empat tulisan utama dan dimaksudkan agar para pembaca dapat memahami lebih lanjut mengenai aspek implementasi pengendalian moneter dengan inflasi sebagai sasaran tunggal, antara lain meliputi pengendalian moneter dalam sistem nilai tukar fleksibel, perilaku nilai tukar rupiah riil dan alternatif nilai tukar rupiah keseimbangan, kestabilan permintaan uang di Indonesia sebelum dan sesudah krisis. A gar implementasi kebijakan moneter lebih mudah dipahami lagi, dalam edisi ini juga disajikan evaluasi mengenai kondisi dan respon kebijakan moneter selama krisis tahun 1997/ 98.

Dalam tulisan Wijoyo Santoso bersama Iskandar mengenai pengendalian moneter dalam sistem nilai tukar fleksible, dapat disarikan bahwa dalam sistem nilai tukar mengambang penuh, peranan suku bungajangka pendek, yakni suku bunga PUA Bovernight, secara empiris terbukti lebih efektif dal am memberikan transmisi kepada suku bungajangka panjang lainnya seperti SBI, deposito, dan kredit. N amun suku bungajangka pendek tersebut tidak memiliki korelasi yang kuat terhadap sasaran akhir inflasi. Oleh karenanya, penggunakan indeks kondisi moneter (IKM) rill menjadi lebih berarti sebagai sasaran antara menuju sasaran akhir inflasi, karena IKM riil memiliki hubungan yang sangat dekat dengan inflasi. Dengan demikian, dalam sistem nilai tukar Rupiah yang mengambang penuh, penggunaan suku bunga, misalnya SBI 1 bulan, sebagai sasaran operasional kebijakan moneter menjadi lebih relevan. Pengendalian moneter dengan suku bunga sebagai sasaran operasional, selain cenderung lebih sustainable dalam jangka menengah dan panjang

\footnotetext{
*) Wijoyo Santoso : Kepala Bagian Studi Ekonomi Makro, Direktorat Riset Ekonomi dan Kebijakan Moneter, Bank Indonesia.
} 
dibandingkan dengan base money sebagai sasaran operasional, juga diharapkan dapat memberikan signal-signal yang lebih mudah ditangkap oleh masyarakat sehingga mereka dapat dengan mudah menilai arah kebijakan moneter: apakah ekspansif atau kontrakstif. Kesimpulan ini juga memperkuat hasil penelitian sebelumnya oleh Perry Warjiyo dan Doddy Zulverdi ${ }^{1}$. Dalam sistem nilai tukar rupiah mengambang penuh kebijakan sterilisasi menjadi kurang dominan karena surplus atau defisit neraca pembayaran dapat disesuaikan secara otomatis melalui apresiasi atau depresiasi nilai tukar rupiah yang ditetapkan oleh pasar sehinga neraca pembayaran selalu dalam posisi ekuilibirum dan cadangan devisa relatif cenderung stabil.

Mengenai jenis inflasi yang relevan untuk menjadi sasaran akhir kebijakan moneter, hasil penelitian juga memperkuat hasil penelitian sebelumnya² bahwa jenis inflasi yang relevan menjadi sasaran akhir kerbijakan moneter adalah underlying inflation, yakni inflasi yang secara langsung dapat dipengaruhi oleh kebijakan moneter. Dalam konteks sekarang ini, oleh karena pengendalian moneter sampai saat ini masih bertumpu pada jumlah uang beredar, khususnya basemon ey, maka pengertian underlying inflation menjadi erat kaitannya dengan besar kecilnya ekses permintaan base money dari masyarakat. Makalah ini secara komprehensif juga menyoroti penggunaan underlying inflation dalam kerangka penerapan inflation targeting di berbagai negara. Model pengendalian moneter ala Bundesbank atau Federal Reserves, kemungkinan dapat menjadi acuan bagi Bank Indonesia di masa mendatang. Untuk tahun 2000, Bank Indonesia telah mencoba untuk mentargetkan underlying inflation (di luar administered prices) sekitar 3-5 persen.

U nderlying Inflation sebagai sasaran akhir tidak berarti bahwa Bank Indonesiakurang memperhatikan gejolak nilai tukar rupiah. Dalam sistem nilai tukar fleksibel, Bank Indonesia tetap berperan dalam menjaga stabilitas nilai tukar rupiah dalm arti bertanggung jawab untuk meredam gejolak nilai tukar yang berlebihan. Untuk keperluan dimaksud, Bank Indonesia perlu mengetahui nilai tukar keseimbangan rupiah jangka panjang maupun pendek yang sesuai dengan faktor-faktor yang mempengaruhinya. Penelitian keseimbangan nilai tukar Rupiah yang dilakukan oleh Yati Kurniati dan A.V. Hardiyanto ini menggunakan pendekatan Behavioral Equilibirum Exchange Rate (BEER) yang diturunkan dari persamaan risk adjusted interest parity yang dinyatakan dalam bentuk riil. Persamaan BEER menunjukkan bahwa keseimbangan jangka panjang nilai tukar riil ditentukan oleh perbedaan suku bunga riil, risk premium, dan ekspektasi nilai tukar yang ditentukan oleh perkembangan faktor-

1 Perry Warjiyo dan Doddy Zulverdi, Penggunaan Suku Bunga sebagai sasaran Operasional Kebijakan Moneter di Indonesia, Buletin Ekonomi Moneter dan Perbankan, Volume1, Nomonr 1, Juli 1998.

2 Lihat Wijoyo Santoso dan Reza Anglingkusumo, Underlying Inflation sebagai Indikator yang relevan dengan Kebijakan Moneter, Buletin Ekonomi Moneter dan Perbankan, Volume1, Nomonr 1, Juli 1998. 
faktor fundamental ekonomi seperti terms of trade, produktivitas dan cadangan devisa. Dengan membandingkan nilai tukar BEER dan Real Effective Exchange Rate (REER) ${ }^{3}$ dapat diukur misalignment nilai tukar rupiah yang dapat digunakan sebagai ukuran ekspektasi perubahan perilaku pasar terhadap nilai tukar rupiah. Hasil studi empiris dari penelitian ini menunjukkan bahwa sejak diterapkannya sistem nilai tukar mengambang penuh, nilai tukar REER dan BEER cenderung konvergen. $\mathrm{Hal}$ ini memperlihatkan bahwa dalam sistem nilai tukar mengambang bebas, perubahan-perubahan ekspektasi masyarakat yang tercermin dalam variabel fundamental dan resiko dapat dengan cepat diterjemahkan oleh pasar sehingga nilai tukar riil aktual mendekati nilai tukar keseimbangan. Selain itu, hasil sampel juga menunjukkan bahwa dalam periode 1996-97 (sebelum krisis), nilai REER cenderung overvalued dibandingkan nilai BEER-nya.

Dalam tulisannya mengenai kestabilan permintaan uang di Indonesia sebelum dan selama masa krisis, Triatmo Doriyanto, menyajikan bukti empiris bahwa permintaan uang riil di Indonesia sebelum dan selama masa krisis cukup stabil. Perubahan-perubahan yang signifikan yang terjadi pada permintaan uang riil karena adanya krisis dapat dijelaskan dengan baik oleh perubahan-perubahan pada variabel-variabel yang secara historismemang mempengaruhi permintaan uang di Indonesia. Analisis mengenai kestabilan permintaan uang riil tersebut menggunakan anal isis kointegrasi yang menunjukkan bahwa permintaan uang riil memiliki hubungan kointegrasi kuat dengan PDB riil dan memiliki nilai parameter yang stabil, sebelum dan seduah krisis. Walaupun hasil penelitian ini masih mendukung penggunaan basemoney sebagai sasaran operasional, namun dalamjangka menengah panjang pengendalian moneter seperti ini tidak sustainable karena sangat costly bagi Bank Indonesia.

Makalah keempat, yang ditulis oleh Charles Joseph, Arief Hartawan dan Firman Mochtar, ingin memberikan evaluasi kondisi dan respon kebijakan yang dilakukan oleh Pemerintah dan Bank Indonesia dalam masa krisis 1997-1998. A danya al iran modal keluar dalam jumlah besar dan dal am waktu singkat telah menyebabkan perekonomian mengalami krisis yang dalam. Kondisi perekonomian semakin parah karena pada saat yang bersamaan sektor keuangan dan sektor kegiatan usaha dalam keadaan rapuh. Dalam situasi sulit tersebut, pengambil kebijakan menghadapi pilihan yang dilematis (policy dilemma) sehingga terkesan adanya keragu-raguan. Pilihan kebijakan yang memfokuskan pada upayastabilisasi jangka pendek melalui kebijakan moneter dan fiskal yang kontraktif telah berhasil mengembalikan kepercayaan dan kestabilan indikator penting ekonomi makro seperti inflasi dan nilai tukar. Namun, pencapaian stabilitas jangka pendek tersebut pada saat perekonomian mengalami aliran modal keluar yang cukup besar mengakibatkan

3 REER adalah indeks nilai tukar rupiah per trading partners' currency yang dibobot dengan total ekspor impor negara-negara partner dagang Indonesia. 
perekonomian mengalami kontraksi yang cukup dalam di tahun 1998. Hal ini diperkuat oleh hasil simulasi model yang menunjukkan bahwa untuk mengatasi aliran modal keluar yang besar, kebijakan tersebut di satu sisi dapat menurunkan inflasi dan memperkuat nilai tukar rupiah. Namun, di sisi lain kombinasi kebijakan tersebut mengakibatkan kontraksi perekonomian. Berdasarkan kajian yang telah dilakukan kebijakan yang diperlukan untuk mempercepat pemulihan perekonomian akibat adanya shock aliran modal keluar adalah kombinasi kontraksi di sisi moneter dan ekpansif di sisi fiskal yang dilakukan secara bertahap. Hasil simulasi model penerapan kombinasi kebijakan moneter dan fiskal untuk pemulihan perekonomian tersebut memperlihatkan hasil laju inflasi yang lebih rendah dengan nilai tukar yang lebih kuat serta kontraksi perekonomian yang lebih kecil dari yang sebenarnya terjadi. 